\title{
Capaian Kemampuan Mathematical Thinking Siswa melalui Model Comprehensive Mathematics Instructions
}

\author{
Nita Delima ${ }^{1 *}$, Yaya S. Kusumah ${ }^{2}$, Siti Fatimah ${ }^{3}$ \\ ${ }^{1}$ Program Studi Pendidikan Matematika, Universitas Subang \\ ${ }^{2,3}$ Program Studi Pendidikan Matematika, Universitas Pendidikan Indonesia \\ *nitadelima1985@gmail.com
}

\begin{abstract}
Abstrak
Hasil ujian nasional yang menunjukkan bahwa siswa masih kesulitan dalam menyelesaikan soal-soal dengan standarisasi PISA memperkuat alasan mengapa skor literasi matematis siswa Indonesia dalam PISA masih sangat rendah. Literasi matematis ini merupakan bagian dari kemampuan mathematical thinking, sehingga dengan membangunnya akan berdampak pada literasi matematis siswa. Model comprehensive mathematics instruction (CMI) diduga dapat membangun kemampuan mathematical thinking siswa. Penelitian ini bertujuan untuk mendeskripsikan capaian kemampuan mathematical thinking siswa yang memperoleh pembelajaran dengan model CMI. Selain itu, penelitian ini juga menganalisis capaian indikator kemampuan mathematical thinking siswa melalui model CMI dengan memperhatikan pengetahuan awal matematika (PAM). Penelitian ini merupakan penelitian eksperimen semu. Sampel diambil secara purposif dari populasi siswa SMA di Subang. Hasil penelitian menunjukkan bahwa capaian kemampuan mathematical thinking siswa yang memperoleh model CMI berbeda secara signifikan dengan siswa yang memperoleh model konvensional. Perbedaan capaian kemampuan generalizing, conjecturing dan convincing antara siswa yang memperoleh model CMI dengan yang memperoleh model konvensional terjadi pada siswa dengan PAM sedang. Dengan demikian, model CMI efektif untuk membangun kemampuan mathematical thinking siswa.

Kata kunci: conjecturing, convincing, generalizing, kemampuan mathematical thinking, model CMI, specializing
\end{abstract}

\begin{abstract}
The national exam results show that students still have difficulty solving PISA standardization questions, reinforcing the reason why Indonesian students' mathematical literacy scores on PISA are still very low. This mathematical literacy is part of the mathematical thinking ability, so building it will impact students' mathematical literacy. The comprehensive mathematics instruction (CMI) model is thought to build students' mathematical thinking abilities. This study aims to describe students' mathematical thinking achievement who obtain learning with the CMI model. Besides, this study also analyzed the achievement of students' mathematical thinking through the CMI model by paying attention to the prior knowledge of mathematics (PAM). This research is a quasi-experimental study. Samples were taken purposively from the population of high school students in Subang. The results showed that the achievement of students' mathematical thinking through the CMI model differed significantly from students' mathematical thinking abilities through conventional models. The difference in the achievement of generalizing, conjecturing, and convincing abilities between students who get CMI model learning and those who get conventional model learning occurs in students with moderate PAM. Thus, the CMI model is effective for building students' mathematical thinking abilities.

Keywords: CMI model, convincing, generalizing, conjecturing, mathematical thinking, specializing
\end{abstract}




\section{Pendahuluan}

Pembelajaran matematika di kelas harus merefleksikan cara kerja seorang matematikawan (Breen \& O'shea, 2010). Matematikawan menggunakan kemampuan mathematical thinking dalam kegiatan bermatematika. Kemampuan mathematical thinking meliputi aspek specialization, generalization, conjecturing, abstraction, reasoning and proving (Bass, 2005; Mason \& Johnston-Wilder, 2004; dan Breen \& O'shea, 2010). Mason et al. (2010) mengemukakan bahwa terdapat empat proses yang paling mendasari terbentuknya kemampuan mathematical thinking, yakni: specializing (kemampuan siswa dalam mencoba beberapa soal, dengan melihat contoh); generalizing (kemampuan siswa dalam mencari pola dan hubungan); conjecturing (kemampuan siswa dalam memprediksi hubungan dan hasil); dan convincing (kemampuan siswa dalam menemukan dan mengkomunikasikan alasan mengapa sesuatu itu benar).

Puspendik (Kemdikbud, 2019) dalam rangkuman eksekutif hasil ujian nasional (UN) SMA tahun 2019 mengemukakan bahwa sebagian besar siswa belum mampu menyelesaikan soal-soal non rutin level berpikir tingkat tinggi (higher order thinking skill). Soal kemampuan berpikir tingkat tinggi setara dengan soal literasi matematis yang dikeluarkan oleh PISA. Sementara itu, hasil PISA 2018 menemukan bahwa ranking literasi matematis siswa Indonesia berada pada posisi ke-74 dari 79 negara yang turut serta dalam survey PISA (OECD, 2019). Stacey (2006) mengemukakan bahwa literasi matematis yang diukur oleh PISA merupakan bagian dari kemampuan mathematical thinking. Dengan demikian, data tersebut juga menunjukkan bahwa kemampuan mathematical thinking siswa SMA masih rendah.

Kemampuan mathematical thinking dapat dikonstruksi melalui pembentukan atmosfir belajar yang tepat, seperti memberikan pertanyaan, memberikan tantangan dan merefleksikan (Stacey, 2006). Kurikulum 2013 telah mengakomodir beberapa aktivitas yang disebutkan di atas pada proses pembelajaran matematika siswa di SMA. Salah satu model pembelajaran yang digunakan di SMA dengan Kurikulum 2013 adalah model pembelajaran berbasis masalah. Model ini memiliki kelemahan pada struktur pedagogis yang belum tersusun dengan sistematis mengikuti alur berpikir siswa SMA (Delima \& Fitriza, 2017). Pengkombinasian model pembelajaran berbasis masalah dengan kerangka comprehensive mathematics instruction (CMI) mampu menyediakan struktur pedagogis bagi guru untuk membimbing alur berpikir siswa dalam membangun ide, strategi dan representasi awal matematis agar dapat berkembang menjadi sebuah definisi dan sifat, prosedur, dan juga model matematis sehingga 
lebih sistematis (Delima \& Fitriza, 2017). Model ini dikenal sebagai model comprehensive mathematics instruction (CMI).

Model CMI memiliki tiga tahapan yakni develop understanding, solidify understanding dan practice understanding (Hendrickson et al., 2008). Ketiga tahap tersebut mengakomodir tentang sistematisasi pemberian masalah, sehingga memunculkan proses pengembangan ide, strategi dan representasi siswa menuju definisi dan sifat, prosedur, serta model yang disebut sebagai continuum of mathematical understanding (Hendrickson, Hilton \& Bahr, 2008). Proses continuum of mathematical understanding dalam model CMI ini akan melibatkan proses-proses specializing, generalizing, conjecturing dan convincing, sehingga memungkinkan peningkatan kemampuan mathematical thinking siswa (Delima \& Fitriza, 2017).

Penelitian tentang kemampuan mathematical thinking telah dilakukan oleh Ersoy \& Güner (2015) yang menemukan bahwa problem solving memberikan efek yang positif terhadap mathematical thinking. Sementara itu, Mason (2020) mengatakan bahwa kemampuan mathematical thinking dapat dikembangkan melalui pemberian soal-soal matematis yang mampu menumbuhkan kegiatan being mathematics seperti specializing, generalizing, conjecturing dan convincing. Delima et al. (2019) menemukan bahwa model CMI mampu meningkatkan mathematics self-concept (MSC) siswa. Delima et al. (2018) juga mengemukakan bahwa terdapat hubungan antara kemampuan mathematical thinking dengan MSC siswa. Penelitian ini memiliki unsur kebaruan dalam aspek penelaahan keterkaitan penerapan model CMI dengan capaian kemampuan mathematical thinking siswa.

Pengetahuan awal merupakan pengetahuan atau keterampilan yang telah dimiliki siswa sebelum mengikuti mata pelajaran yang akan diberikan (Dick \& Lou, 2005). Selain itu, pengetahuan awal merupakan sebuah modal bagi siswa untuk mengatasi masalah pada saat pembelajaran berlangsung (Fernández et al., 2018). Dengan demikian, jika PAM yang dimiliki siswa tinggi akan mengakibatkan pencapaian yang baik. Oleh karena itu, pada kesempatan kali ini penulis tertarik untuk menguji keefektifan model dalam pencapaian kemampuan mathematical thinking siswa berdasarkan PAM yang dimiliki siswa. Penelitian ini bertujuan untuk mendeskripsikan capaian kemampuan mathematical thinking siswa yang memperoleh pembelajaran dengan model CMI. Selain itu, penelitian ini juga menganalisis capaian indikator kemampuan mathematical thinking siswa melalui model CMI dengan memperhatikan pengetahuan awal matematika (PAM). 


\section{Metode}

Penelitian ini merupakan penelitian eksperimental semu. Pemilihan studi ini didasarkan pertimbangan bahwa, kelas yang ada telah terbentuk sebelumnya dan tidak mungkin dilakukan pengelompokan siswa secara acak. Penelitian ini menggunakan pendekatan kuantitatif. Desain penelitian yang digunakan adalah nonequivalent control group design. Populasi penelitian ini adalah seluruh siswa SMA kelas XI di Subang, Jawa Barat, Indonesia. Pengambilan sampel dilakukan dengan purposive sampling, yaitu pengambilan sampel berdasarkan pertimbangan nilai rata-rata UN mata pelajaran matematika di seluruh SMA di Subang, Jawa Barat, Indonesia. Dalam penelitian ini SMA Negeri 3 Subang ditetapkan sebagai sekolah sampel. Teknik pengumpulan data penelitian ini menggunakan dua jenis instrumen yaitu instrumen tes berupa soal uraian untuk mengukur PAM dan kemampuan mathematical thinking serta instrumen non tes berupa lembar observasi untuk mengamati penerapan model CMI.

Instrumen tes kemampuan mathematical thinking, menggunakan indikator kemampuan mathematical thinking yang dikemukakan oleh Mason, Burton dan Stacey (2010), yakni: (a) Specializing, mencoba soal dengan melihat contoh, memperhatikan kasus yang sederhana; (b) Generalizing, mencari pola dan hubungan; (c) Conjecturing, memprediksi hubungan dan hasil; (d) Convincing, menemukan dan mengkomunikasikan alasan mengapa sesuatu itu benar. Penelitian ini dilakukan untuk materi ajar transformasi geometri juga barisan dan deret tak hingga. Berikut ini beberapa instrumen tes kemampuan mathematical thinking yang digunakan dalam penelitian ini.

Tabel 1. Instrumen Tes Kemampuan Mathematical Thinking

\begin{tabular}{|c|c|c|}
\hline Materi Ajar & Indikator & Butir Soal \\
\hline $\begin{array}{c}\text { Transformasi } \\
\text { Geometri }\end{array}$ & $\begin{array}{l}\text { Indikator kemampuan mathematical } \\
\text { thinking yang diukur pada soal ini adalah } \\
\text { specializing. Pada soal ini, siswa } \\
\text { diharapkan dapat mencoba soal dengan } \\
\text { terlebih dahulu memperhatikan kasus } \\
\text { yang sederhana, seperti mencoba } \\
\text { menentukan posisi titik pada translasi } \\
\text { pertama, kemudian menentukan posisi } \\
\text { titik pada translasi kedua, sampai } \\
\text { akhirnya siswa dapat menemukan cara } \\
\text { yang sederhana dalam menyelesaikan } \\
\text { masalah tersebut. }\end{array}$ & $\begin{array}{l}\text { 1. Titik } A(-2,1) \text { ditranslasikan berturut- } \\
\text { turut dengan translasi } \\
T_{n}=(2 n-1, n+2) \text { untuk } n \in \mathrm{N} \text {. } \\
\text { Tentukan posisi titik pada translasi ke- } \\
2017 \text {. }\end{array}$ \\
\hline \multirow[t]{2}{*}{$\begin{array}{c}\text { Barisan dan } \\
\text { Deret Tak } \\
\text { Hingga }\end{array}$} & $\begin{array}{l}\text { Indikator kemampuan mathematical } \\
\text { thinking yang diukur pada soal ini } \\
\text { dijelaskan sebagai berikut. }\end{array}$ & $\begin{array}{l}\text { 2. Perhatikan barisan bilangan berikut: } \\
2, \frac{1}{2}, \frac{1}{8}, \frac{1}{32}, \ldots\end{array}$ \\
\hline & $\begin{array}{l}\text { Soal ini mengukur indikator } \\
\text { generalizing. Soal tersebut, mengarahkan } \\
\text { siswa ke dalam proses melihat } \\
\text { kekhususan/ pola pada setiap suku. }\end{array}$ & a. Tentukan tiga suku berikutnya. \\
\hline
\end{tabular}


Soal ini mengukur indikator generalizing. Soal tersebut, mengarahkan siswa ke dalam proses melihat kekhususan/ pola pada setiap suku.

Soal ini mengukur indikator generalizing. Soal tersebut, mengarahkan siswa ke dalam proses melihat kekhususan/ pola pada setiap suku. Soal ini untuk mengukur indikator conjecturing. Pada soal ini, siswa

b. Tentukan suku ke-10. diarahkan untuk merekognisi proses generalizing pada tiga soal sebelumnya.

Soal ini diberikan untuk mengarahkan siswa pada proses convincing, yakni proses mencari suatu alasan bahwa

c. Jika diketahui nilai dari suku ke$(n-1)$, tentukan nilai suku ke- $n$ dari barisan bilangan tersebut.

konjektur yang mereka temukan pada soal 2.d adalah benar.

Indikator kemampuan mathematical thinking yang diukur pada soal ini adalah

f. Apakah barisan tersebut barisan naik conjecturing dan convincing. Pada soal atau turun? Jelaskan. ini, siswa diarahkan kembali untuk menemukan sebuah konjektur, kemudian mencari alasan apakah konjektur yang mereka buat adalah benar.

Penentuan skor tes kemampuan mathematical thinking dilakukan dengan mengikuti aturan pada pedoman penentuan skor yang tercantum di Tabel 2. Pedoman tersebut diadopsi dari rubrik skor yang digunakan oleh Diezmann (2004) dengan sedikit modifikasi pada penentuan skor minimum dan maksimum. Rubrik skor ini mengelompokkan hasil pekerjaan siswa dalam lima tingkatan kemampuan siswa seperti yang tertera pada tabel 2 berikut.

Tabel 2. Pedoman Penentuan Skor Tes Kemampuan Mathematical Thinking

\begin{tabular}{clc}
\hline Tingkatan & \multicolumn{1}{c}{ Respon Siswa } & Skor \\
\hline No Response & Tidak ada jawaban & 0 \\
\hline Low Response & $\begin{array}{l}\text { Jawaban siswa terlalu sederhana, tidak jelas atau tidak dapat } \\
\text { dijalankan. Penjelasan yang diberikan terbatas atau terjadi } \\
\text { miskonsepsi. }\end{array}$ & 1 \\
\hline $\begin{array}{c}\text { Medium } \\
\text { Response }\end{array}$ & $\begin{array}{l}\text { Jawaban cukup jelas disajikan, penjelasan memadai, dengan rincian } \\
\text { terbatas }\end{array}$ & 2 \\
\hline High Response & $\begin{array}{l}\text { Jawaban disajikan dengan jelas dan mencakup beberapa gagasan } \\
\text { orisinil. Masalah dapat dipahami dengan baik, penjelasan yang } \\
\text { diberikan jelas dan mencakup beberapa detail. }\end{array}$ & 3 \\
\hline Exceptional & $\begin{array}{l}\text { Jawaban yang diberikan sangat jelas mencakup beberapa strategi } \\
\text { Response }\end{array}$ & $\begin{array}{l}\text { yang menunjukkan pemikiran orisinal dan canggih pada kelasnya. } \\
\text { Jawaban tersebut mengungkapkan kemampuan untuk memikirkan } \\
\text { masalah yang kompleks, penjelasannya jelas dan efektif serta } \\
\text { mencakup rincian yang relevan. }\end{array}$ \\
\hline
\end{tabular}

Berdasarkan hasil analisis instrumen yang telah dilakukan diperoleh nilai koefisien korelasi untuk mengukur validitas berturut-turut adalah 0,$362 ; 0,399 ; 0,815 ; 0,827 ; 0,808$; 0,436; 0,303 dengan mengacu pada kriteria Cohen et al. (2007), butir soal yang digunakan dalam penelitian ini adalah butir soal yang valid. Koefisien reliabilitas yang diperoleh sebesar 
0,805 sehingga instrumen ini memiliki reliabilitas tinggi (Cohen et al., 2007). Indeks daya pembeda serta interpretasinya yang mengacu pada Cohen et al. (2007) yang dimiliki instrumen ini berturut-turut adalah 0,375 (interpretasi cukup); 0,833 (baik); 0,958 (baik); 1,000 (baik); 1,000 (baik); 1,000 (baik); 1,000 (baik), berdasarkan hasil tersebut dilakukan perbaikan kalimat pada soal nomor satu. Instrumen ini memiliki indeks nilai tingkat kesukaran dan interpretasinya yang mengacu pada Cohen et al. (2007) berturut-turut 0,292 (sukar); 0,563 (sedang); 0,521 (sedang); 0,500 (sedang); 0,500 (sedang); 0,500 (sedang); 0,500 (sedang). Untuk melihat capaian kemampuan mathematical thinking dilakukan pengelompokkan data skor tes kemampuan mathematical thinking. Pengelompokkan data kemampuan mathematical thinking dilakukan dengan menyusun tabel distribusi frekuensi dari skor nilai tes kemampuan mathematical thinking siswa. Tabel distribusi frekuensi ini memiliki banyak kelas sebanyak tiga buah, sesuai dengan kategori kemampuan mathematical thinking yakni rendah, sedang dan tinggi (Delima et al., 2018). Berikut adalah tabel kategori kemampuan mathematical thinking.

Tabel 3. Kategori Kemampuan Mathematical Thinking

\begin{tabular}{lll}
\hline Data & Kategori & Skor \\
\hline Kemampuan Mathematical Thinking & Rendah & $0 \leq \mathrm{KMT}<12$ \\
\cline { 2 - 3 }$(\mathrm{KMT})$ & Sedang & $12 \leq \mathrm{KMT}<24$ \\
\cline { 2 - 3 } & Tinggi & $24 \leq \mathrm{KMT} \leq 36$ \\
\hline
\end{tabular}

Tes PAM digunakan untuk mengetahui PAM siswa sebelum pembelajaran berlangsung, sekaligus untuk mengelompokkan siswa menurut kemampuannya, yaitu siswa yang berkemampuan tinggi, sedang dan rendah. Tes PAM ini berupa lima butir soal uraian tentang materi pelajaran sebelum penelitian ini dilakukan yakni matriks. Nilai koefisien korelasi untuk mengukur validitas instrumen ini serta interpretasinya menurut Cohen et al. (2007) berturut-turut adalah 0,$561 ; 0,696 ; 0,773 ; 0,794 ; 0,834$. Koefisien reliabilitas yang dimiliki instrumen ini sebesar 0,735 dengan interpretasi tingkat reliabilitasnya tinggi. Materi matriks diambil dengan pertimbangan bahwa materi ini merupakan prasyarat untuk memperlajari tranformasi geometri. Pengelompokkan hasil tes PAM dilakukan dengan membuat tabel distribusi frekuensi skor tes sehingga diperoleh kriteria pengelompokkan level PAM siswa seperti pada tabel 4 berikut.

Tabel 4. Kriteria Pengelompokkan Level PAM

\begin{tabular}{lccc}
\hline \multirow{2}{*}{ Interval skor PAM } & \multirow{2}{*}{ Level } & \multicolumn{2}{c}{ Banyak Siswa } \\
\cline { 2 - 4 } & & Kelas CMI & Kelas Konvensional \\
\hline $10 \leq$ skor $P A M<14$ & Rendah & 16 & 4 \\
\hline $14 \leq$ skor $P A M<18$ & Sedang & 10 & 21 \\
\hline $18 \leq$ skor $P A M<22$ & Tinggi & 11 & 9 \\
\hline Total & & 37 & 34 \\
\hline
\end{tabular}


Terdapat dua perangkat pembelajaran yang digunakan dalam penelitian ini, yakni lembar kerja siswa (LKS) dan rencana pelaksanaan pembelajaran (RPP). Perangkat pembelajaran yang digunakan dirancang dan dikembangkan sesuai dengan karakteristik dari model CMI dengan mempertimbangkan kemampuan mathematical thinking yang akan dicapai siswa. Pengembangan perangkat pembelajaran juga disesuaikan dengan tuntutan kurikulum di sekolah yakni Kurikulum 2013. LKS yang digunakan dalam penelitian ini memuat materi transformasi geometri serta barisan dan deret tak hingga. LKS disusun sesuai dengan tahapan pada model CMI serta memuat seluruh indikator kemampuan mathematical thinking. Validasi LKS dilakukan dengan menguji coba secara terbatas serta meminta pertimbangan dari ahli untuk mengetahui tingkat keterbacaan bahasa sekaligus memperoleh gambaran apakah LKS dapat dipahami siswa dengan baik. Sementara itu, RPP memuat desain didaktis yang dijadikan panduan bagi guru dalam melaksanakan pembelajaran, khususnya terkait dengan bagaimana menerapkan model CMI dengan memanfaatkan LKS sebagai sumber belajar siswa.

Teknik analisis data yang digunakan dalam penelitian statistika deskriptif, uji normalitas Kolmogorov-Smirnov, uji homogenitas Levene, uji-t, uji Mann-Whitney U Dokumentasi data kualitatif berupa hasil observasi selama pembelajaran berlangsung diolah untuk melihat kesesuaian pelaksanaan pembelajaran di kelas dengan rencana pelaksanaan pembelajaran. Hasil analisis ini memperkuat data kuantitatif yang telah diperoleh, sehingga mempertajam penarikan kesimpulan.

\section{Hasil Penelitian}

Data pencapaian kemampuan mathematical thinking siswa diperoleh dari nilai tes siswa setelah pembelajaran dilaksanakan. Deskripsi statistik data dapat dilihat pada Tabel 5 berikut.

Tabel 5. Statistik Data Tes Kemampuan Mathematical Thinking Siswa

\begin{tabular}{|c|c|c|c|c|c|c|c|}
\hline \multirow{2}{*}{ Model } & \multirow{2}{*}{ PAM } & \multicolumn{2}{|c|}{ Nilai Tes } & \multirow{2}{*}{ Model } & \multirow{2}{*}{ PAM } & \multicolumn{2}{|c|}{ Nilai Tes } \\
\hline & & Mean & SD & & & Mean & SD \\
\hline \multirow[t]{4}{*}{ CMI } & Rendah & 25,930 & 3,674 & \multirow[t]{4}{*}{ Konvensional } & Rendah & 23,000 & 1,581 \\
\hline & Sedang & 26,750 & 3,151 & & Sedang & 22,500 & 3,832 \\
\hline & Tinggi & 25,220 & 2,728 & & Tinggi & 26,330 & 3,041 \\
\hline & $\overline{\text { Total }}$ & 25,940 & 3,252 & & Total & 23,590 & 3,718 \\
\hline
\end{tabular}

Pada Tabel 5 terlihat bahwa nilai tes siswa yang memperoleh pembelajaran CMI lebih besar daripada siswa yang memperoleh pembelajaran konvensional dengan selisih rata-rata 2,350. Rata-rata nilai tes untuk semua siswa yang menerima pembelajaran CMI adalah 25,940. Nilai tersebut berada pada kategori kemampuan mathematical thinking tinggi. 
Sedangkan rata-rata nilai tes seluruh siswa dengan pembelajaran konvensional adalah 23,590. Nilai tersebut berada pada kategori kemampuan mathematical thinking sedang.

Selanjutnya, untuk menunjukkan apakah terdapat perbedaan yang signifikan antara pencapaian kemampuan mathematical thinking siswa yang memperoleh model CMI dengan yang memperoleh model konvensional, maka dilakukan pengujian hipotesis. Namun, sebelumnya terlebih dahulu dilakukan uji prasyarat berupa uji normalitas. Uji normalitas dilakukan dengan menggunakan uji Kolmogorov-Smirnov. Hasil uji normalitas menunjukkan bahwa data skor tes siswa yang memperoleh CMI tidak berdistribusi normal. Oleh karena itu, pengujian hipotesis dilakukan dengan menggunakan uji Mann-Whitney U. Rangkuman hasil uji Mann-Whitney U disajikan pada tabel 6 berikut.

Tabel 6. Hasil Uji Mann-Whitney U Data Tes Kemampuan Mathematical Thinking

\begin{tabular}{lcc}
\hline Model & Mann-Whitney U & Asymp. Sig. (2-tailed) \\
\hline CMI : Konvensional & 352,000 & 0,013 \\
\hline
\end{tabular}

Tabel 6 menunjukkan nilai Sig. yang diperoleh adalah 0,013, maka H0 ditolak. Dengan kata lain, pencapaian kemampuan mathematical thinking siswa yang memperoleh model CMI dengan siswa yang memperoleh model konvensional berbeda secara signifikan.

Untuk mengetahui ada tidaknya perbedaan pencapaian kemampuan mathematical thinking yang signifikan antara siswa yang memperoleh model CMI dengan siswa yang memperoleh model konvensional berdasarkan PAM yang dimilikinya, maka dilakukan pengujian hipotesis dengan memperhatikan PAM siswa. Namun, sebelumnya dilakukan uji normalitas dan homogenitas terlebih dahulu. Hasil dari kedua pengujian tersebut menunjukkan bahwa setiap pasangan data memiliki distribusi normal dan homogen. Dengan demikian, pengujian hipotesis berbasis PAM dilakukan dengan menggunakan uji-t sebagai berikut.

Tabel 7. Hasil Uji-t Capaian Kemampuan Mathematical Thinking berdasarkan PAM

\begin{tabular}{llccc}
\hline PAM & Models & $\mathbf{t}$ & $\boldsymbol{d f}$ & Sig. (2-tailed) \\
\hline Rendah & CMI : Conventional & 1,709 & 18 & 0,105 \\
\hline Sedang & CMI : Conventional & 2,775 & 26 & 0,010 \\
\hline Tinggi & CMI : Conventional & $-0,816$ & 16 & 0,427 \\
\hline
\end{tabular}

Tabel 7 menunjukkan bahwa nilai Sig. sebesar 0,010 diperoleh kelompok siswa dengan PAM sedang. Dengan demikian, pada kategori ini HO ditolak, artinya perbedaan pencapaian kemampuan mathematical thinking yang signifikan antara siswa yang memperoleh model CMI dengan yang memperoleh model konvensional hanya terjadi pada siswa dengan PAM sedang. 
Kemampuan mathematical thinking siswa dibangun oleh empat indikator yakni specializing, generalizing, conjecturing dan convincing. Berikut ini deskripsi statistik kemampuan mathematical thinking pada setiap indikatornya.

Tabel 8. Statistik Indikator Kemampuan Mathematical Thinking berdasarkan PAM

\begin{tabular}{llllllllll}
\hline Model & \multirow{2}{*}{ PAM } & \multicolumn{3}{c}{ Specializing } & \multicolumn{2}{c}{ Generalizing } & \multicolumn{2}{c}{ Conjecturing } & \multicolumn{2}{c}{ Convincing } \\
\cline { 2 - 10 } & & Mean & SD & Mean & SD & Mean & SD & Mean & SD \\
\hline \multirow{3}{*}{ CMI } & Rendah & 2,689 & 0,427 & 3,333 & 0,356 & 2,767 & 0,623 & 2,767 & 0,623 \\
\cline { 2 - 10 } & Sedang & 2,792 & 0,533 & 3,375 & 0,330 & 2,938 & 0,417 & 2,938 & 0,417 \\
\cline { 2 - 10 } & Tinggi & 2,593 & 0,278 & 3,185 & 0,377 & 2,889 & 0,417 & 2,889 & 0,417 \\
\cline { 2 - 9 } & Total & 2,688 & 0,414 & 3,302 & 3,353 & 2,844 & 0,515 & 2,844 & 0,515 \\
\hline Konvensional & Rendah & 2,267 & 0,365 & 3,267 & 0,149 & 2,300 & 0,274 & 2,300 & 0,274 \\
\cline { 2 - 9 } & Sedang & 2,667 & 0,459 & 2,917 & 0,431 & 2,150 & 0,587 & 2,150 & 0,587 \\
\cline { 2 - 9 } & Tinggi & 2,815 & 0,294 & 3,333 & 0,236 & 2,778 & 0,507 & 2,778 & 0,507 \\
\hline \multirow{nyyyyyyyy}{*}{ SMI } & Total & 2,647 & 0,434 & 3,078 & 0,403 & 2,338 & 0,587 & 2,338 & 0,587 \\
\hline
\end{tabular}

Tabel 8 menunjukkan bahwa pada setiap indikator kemampuan mathematical thinking, rata-rata skor siswa yang memperoleh pembelajaran model CMI lebih besar dibandingkan dengan siswa yang memperoleh pembelajaran model konvensional. Akan tetapi, ini tidak berlaku untuk setiap kategori PAM siswa. Siswa yang memperoleh pembelajaran model CMI dengan kategori PAM tinggi memiliki rata-rata specializing dan generalizing lebih kecil dibandingkan dengan kelompok siswa yang memperoleh pembelajaran model konvensional. Sementara itu, siswa yang memperoleh pembelajaran model CMI dengan kategori PAM sedang dan rendah memiliki rata-rata skor specializing dan generalizing lebih besar daripada siswa yang memperoleh pembelajaran model konvensional. Untuk mengetahui apakah perbedaan tersebut signifikan atau tidak, dilakukan pengujian hipotesis. Sebelumnya, dilakukan uji normalitas. Hasil uji normalitas menunjukkan bahwa data skor tes untuk setiap indikator kemampuan mathematical thinking tidak memiliki distribusi normal. Dengan demikian, pengujian hipotesis dilakukan dengan menggunakan uji Mann-Whitney U seperti tabel 9 berikut.

Tabel 9. Hasil Uji Mann-Whitney U Setiap Indikator Kemampuan Mathematical Thinking

\begin{tabular}{llcc}
\hline $\begin{array}{l}\text { Indikator Kemampuan } \\
\text { Mathematical Thinking }\end{array}$ & Model & Mann-Whitney U & Asymp. Sig. (2-tailed) \\
\hline Specializing & CMI : Konvensional & 529,000 & 0,843 \\
\hline Generalizing & CMI : Konvensional & 381,500 & 0,029 \\
\hline Conjecturing & CMI : Konvensional & 282,500 & 0,000 \\
\hline Convincing & CMI : Konvensional & 282,500 & 0,000 \\
\hline
\end{tabular}

Berdasarkan Tabel 9 diperoleh bahwa terdapat perbedaan capaian kemampuan mathematical thinking yang signifikan antara siswa yang memperoleh pembelajaran model 
CMI dengan siswa yang memperoleh pembelajaran model konvensional pada setiap indikatornya, kecuali pada indikator specializing. Hasil ini menandakan bahwa model CMI memberikan manfaat pada capaian setiap indikator kemampuan mathematical thinking, kecuali specializing. Selanjutnya, dilakukan pengujian hipotesis untuk menguji signifikansi perbedaan capaian indikator kemampuan mathematical thinking antara siswa yang memperoleh pembelajaran model CMI dengan siswa yang memperoleh pembelajaran model konvensional berdasarkan PAM. Uji prasyarat berupa uji normalitas dan homogenitas terlebih dahulu dilakukan, sehingga uji hipotesis dilakukan dengan dua jenis uji yakni uji-t dan uji Mann-Whitney U. Hasilnya terlihat seperti tabel 10 berikut.

Tabel 10. Hasil Uji Hipotesis Data Capaian Indikator Kemampuan Mathematical Thinking berdasarkan PAM

\begin{tabular}{llcccc}
\hline \multirow{2}{*}{ Kategori PAM } & \multirow{2}{*}{ Model } & \multicolumn{4}{c}{ Sig. (2-tailed) } \\
\cline { 3 - 6 } & & Specializing & Generalizing & Conjecturing & Convincing \\
\hline Rendah & CMI : Konvensional & $0,073^{*}$ & $0,489^{*}$ & $0,073^{*}$ & $0,073^{*}$ \\
\hline Sedang & CMI : Konvensional & $0,539^{* *}$ & $0,013^{*}$ & $0,003^{*}$ & $0,003^{*}$ \\
\hline Tinggi & CMI : Konvensional & $0,119^{* *}$ & $0,400^{*}$ & $0,618^{* *}$ & $0,618^{* *}$ \\
\hline
\end{tabular}

*menggunakan uji Mann-Whitney U

** menggunakan uji-t

Tabel 10 menunjukkan bahwa perbedaan yang signifikan antara capaian kemampuan mathematical thinking siswa yang memperoleh pembelajaran model CMI dengan yang memperoleh pembelajaran model konvensional terjadi pada siswa dengan PAM sedang, untuk indikator generalizing, conjecturing dan convincing saja. Pada siswa dengan PAM kategori rendah dan tinggi, tidak terdapat perbedaan yang signifikan antara capaian kemampuan mathematical thinking siswa yang memperoleh pembelajaran model CMI dengan yang memperoleh pembelajaran model konvensional pada setiap indikatornya. Dengan kata lain, pembelajaran model CMI hanya efektif untuk meningkatkan indikator generalizing, conjecturing dan convincing pada siswa dengan PAM sedang saja.

Setiap aktivitas pembelajaran dengan model CMI diobservasi untuk mengetahui keterlaksanaan model menggunakan instrumen lembar observasi. Instrumen ini berisi ceklis langkah-langkah pembelajaran menggunakan model CMI sesuai dengan RPP. Observasi dilakukan oleh dua orang, yang terdiri dari satu orang guru dan satu orang teman sejawat. Hasilnya disajikan pada tabel 11 berikut. 
Tabel 11. Hasil Observasi Keterlaksanaan Model CMI

\begin{tabular}{clcccccccc}
\hline \multirow{2}{*}{ No } & Observer & \multicolumn{8}{c}{ Persentase Keterlaksanaan Pertemuan ke- } \\
\cline { 3 - 11 } & & $\mathbf{1}$ & $\mathbf{2}$ & $\mathbf{3}$ & $\mathbf{4}$ & $\mathbf{5}$ & $\mathbf{6}$ & $\mathbf{7}$ & $\mathbf{8}$ \\
\hline 1 & Observer I & 70 & 90 & 100 & 100 & 100 & 100 & 100 & 100 \\
\hline 2 & Observer II & 70 & 83 & 100 & 100 & 100 & 100 & 100 & 100 \\
\hline
\end{tabular}

Tabel 11 menunjukkan bahwa selama enam kali pertemuan, model CMI telah sepenuhnya dilaksanakan sesuai dengan RPP. Pertemuan pertama dan kedua belum terlaksanakan sepenuhnya karena siswa masih dalam proses adaptasi menerima model pembelajaran yang baru.

\section{Pembahasan}

Hasil penelitian menemukan bahwa capaian kemampuan mathematical thinking siswa yang memperoleh pembelajaran model CMI secara signifikan berbeda dengan siswa yang memperoleh pembelajaran model konvensional. Rata-rata nilai tes akhir siswa yang memperoleh pembelajaran model CMI lebih tinggi dari siswa yang memperoleh pembelajaran model konvensional. Temuan tersebut memberikan gambaran bahwa capaian kemampuan mathematical thinking siswa yang memperoleh pembelajaran model CMI secara signifikan lebih baik daripada siswa yang memperoleh pembelajaran konvensional.

Hasil tersebut sejalan penelitian Ersoy dan Güner (2015), dan Delima (2017) yang menemukan bahwa terdapat hubungan yang signifikan antara problem solving dan kemampuan mathematical thinking. Model CMI mengakomodasi tiga tahapan yang komprehensif yakni develop, solidify dan practice (Delima \& Fitriza, 2017). Proses problem solving berlangsung pada tahap develop, ketika guru menyediakan soal/ tugas matematis yang bentuknya open ended. Soal open ended yang diberikan merupakan soal yang dapat menggali serta mengembangkan kemampuan mathematical thinking. Sebagaimana yang dikemukakan oleh Mason (2020) bahwa kemampuan mathematical thinking dapat dikembangkan dan dipertahankan keberlanjutannya dalam diri siswa jika guru mampu membangun soal-soal matematis yang menstimulasi kemampuan specializing, generalizing, conjencturing dan convincing.

Penelitian ini juga diperkuat oleh Gibney (2014), dan Uyangör (2019) yang menemukan bahwa kemampuan mathematical thinking dapat dibangun melalui kesiapan struktur pedagogis guru dalam membimbing siswa mengerjakan tugas-tugas matematis yang realistik juga variatif serta dikerjakan secara berkelompok. Model CMI mampu menyediakan struktur pedagogis bagi guru untuk membimbing alur berpikir siswa dalam membangun ide, strategi 
dan representasi awal matematis agar dapat berkembang menjadi sebuah definisi dan sifat, prosedur, dan juga model matematis sehingga lebih sistematis (Delima \& Fitriza, 2017).

Salah satu komponen dalam CMI adalah continuum of mathematical understanding (Hendrickson et al., 2008), proses-proses konseptualisasi matematis, doing mathematics dan representasi matematis berlangsung secara terus-menerus pada sepanjang garis kontinum yang disediakan oleh komponen learning cycle. Siswa yang terbiasa berpikir mengikuti alur garis kontinum dalam CMI lebih sistematis dalam menyelesaikan soal. Berikut ini diberikan gambaran perbandingan hasil kerja siswa yang memperoleh pembelajaran CMI dan yang memperoleh pembelajaran konvensional pada saat tes akhir.

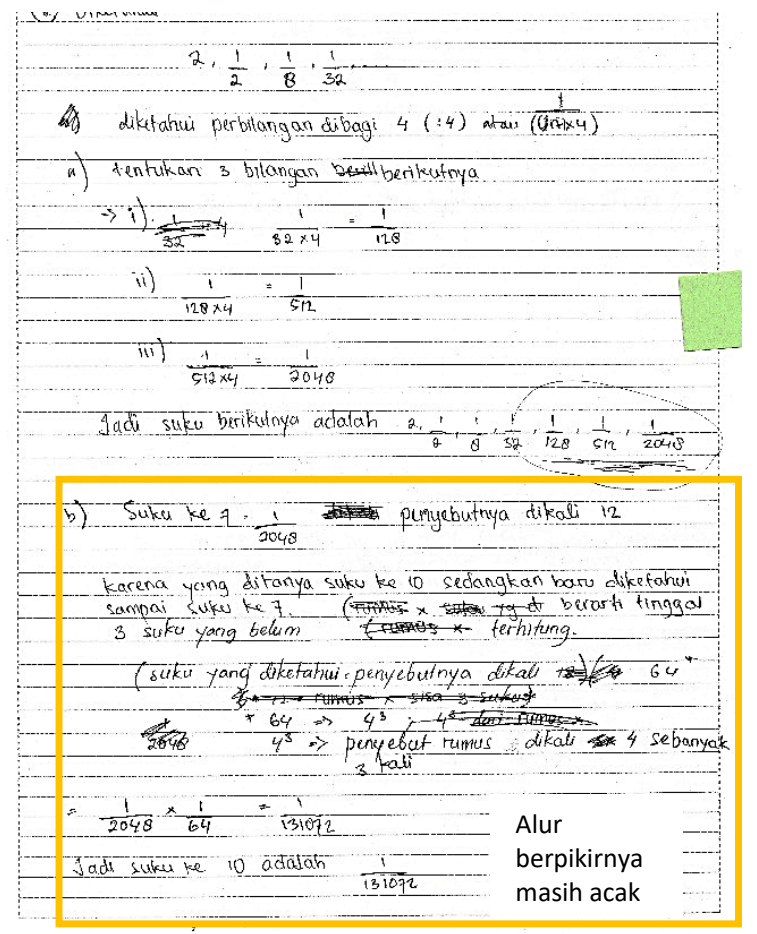

Model konvensional

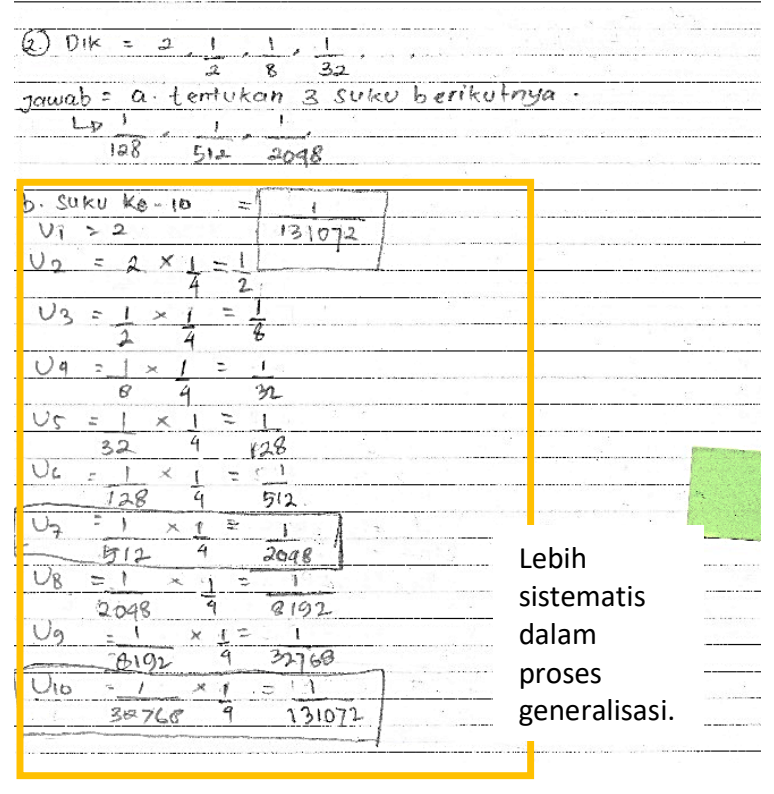

Model CMI

Gambar 1. Hasil Kerja Siswa setelah Pembelajaran Dilaksanakan

PAM merupakan pengetahuan yang telah dimiliki siswa sebelum mengikuti pembelajaran dengan model CMI. Pengetahuan ini dapat memberi kemudahan bagi siswa dalam mempelajari materi yang akan diajarkan guru, sebaliknya, tanpa pengetahuan ini siswa akan mengalami kesulitan mempelajari materi berikutnya (Dick \& Lou, 2005). Fernández et al. (2018) menemukan fakta bahwa level pengetahuan awal akan menentukan bagaimana seseorang menyelesaikan masalah matematisnya. Pada penelitian ini, capaian kemampuan mathematical thinking kelompok siswa dengan PAM sedang yang memperoleh pembelajaran model CMI secara signifikan berbeda dengan yang memperoleh pembelajaran model konvensional. Sementara itu, pada siswa dengan PAM rendah dan tinggi, tidak terdapat 
perbedaan yang signifikan antara capaian kemampuan mathematical thinking siswa yang memperoleh pembelajaran model CMI dengan siswa yang memperoleh pembelajaran model konvensional. Hal ini sejalan dengan penelitian Delima et al. (2019) yang menemukan bahwa model CMI memberikan efek peningkatan MSC yang berbeda pada siswa dengan kategori PAM yang berbeda. Model CMI memberikan preskripsi bagi guru untuk membimbing dan membantu siswa agar dapat berkembang sesuai dengan tahapan perkembangan yang seharusnya (Hendrickson et al., 2008). Selain itu, penelitian Gibney (2014) yang menemukan bahwa untuk menstimulasi kemampuan mathematical thinking dapat dilakukan dengan memberikan tugas-tugas matematis dengan berbagai level problem-solving juga memperkuat hasil penelitian ini. Pembimbingan intensif yang dilakukan oleh guru pada model CMI sangat efektif untuk membantu siswa yang memiliki PAM yang sedang.

Pada penelitian ini, siswa dengan PAM tinggi, tidak memiliki perbedaan yang signifikan antara capaian kemampuan mathematical thinking siswa yang memperoleh pembelajaran model CMI dengan siswa yang memperoleh pembelajaran model konvensional, karena siswa dengan PAM tinggi telah memiliki modal yang besar dalam mengatasi masalah pembelajaran. Modal yang dimaksud adalah bekal pengetahuan yang sejalan dengan materi pembelajaran yang akan diberikan. Bekal pengetahuan ini akan mendukung proses pembelajaran siswa (Fernández et al., 2018; Harefa, 2013), sehingga setiap siswa baik yang memperoleh pembelajaran model CMI maupun yang memperoleh pembelajaran model konvensional lebih mudah dalam memahami pembelajaran.

Sebaliknya dengan siswa yang memiliki PAM rendah, modal pengetahuan yang dimiliki untuk mengatasi masalah pembelajaran terbatas, sehingga diperlukan upaya yang cukup berat bagi guru untuk membimbing siswa agar dapat mengikuti pembelajaran yang diberikan. Model CMI menyediakan bimbingan guru pada setiap tahapannya, akan tetapi, proses pembimbingan ini, tidak membebankan proporsi intensitasnya. Akibatnya siswa dengan PAM rendah memperoleh intensitas bimbingan yang sama dengan siswa PAM tinggi dan sedang. Hal ini yang menyebabkan pada siswa dengan PAM rendah, tidak terdapat perbedaan yang signifikan antara pencapaian kemampuan mathematical thinking siswa yang memperoleh pembelajaran model CMI dengan siswa yang memperoleh pembelajaran model konvensional. Hasil penelitian ini sejalan dengan teori belajar Ausubel bahwa pembelajaran bermakna terjadi jika siswa dapat menghubungkan fenomena baru dengan pengetahuan awal mereka serta tugas-tugas belajar yang diberikan sesuai dengan level intelektual siswa (Harefa, 2013). Dengan demikian, temuan dari penelitian ini memberikan implikasi bahwa pada pelaksanaan 
model CMI, perlu ada perbedaan proporsi intensitas pembimbingan siswa oleh guru berdasarkan PAM.

Capaian kemampuan mathematical thinking dianalisis lebih rinci berdasarkan setiap indikatornya. Adapun indikator yang membangun kemampuan mathematical thinking dalam penelitian ini adalah specializing, generalizing, conjecturing dan convincing. Capaian kemampuan generalizing, conjecturing dan convincing siswa yang memperoleh pembelajaran model CMI secara signifikan lebih baik daripada siswa yang memperoleh pembelajaran model konvensional. Sementara itu, pada indikator specializing, tidak ada perbedaan capaian kemampuan specializing yang signifikan antara siswa yang memperoleh pembelajaran model CMI dengan siswa yang memperoleh pembelajaran model konvensional.

Specializing merupakan kemampuan untuk mencoba beberapa soal dengan melihat contoh serta kemampuan untuk menyederhanakan kompleksitas sebuah masalah (Mason et al., 2010). Pada penelitian ini, pembelajaran model konvensional dilakukan melalui pendekatan pembelajaran berbasis masalah. Permasalahan yang diberikan kepada siswa, merupakan masalah-masalah yang terkait dengan kemampuan specializing. Sebagaimana yang dikemukakan oleh Setiyawan (2017), pembelajaran berbasis masalah dapat mengembangkan keterampilan berpikir siswa, dan keterampilan berpikir siswa yang dikembangkan tergantung pada masalah yang diberikan. Dengan demikian, cukup beralasan bahwa perbedaan capaian kemampuan specializing antara siswa yang memperoleh pembelajaran model CMI dengan siswa yang memperoleh pembelajaran konvensional tidak signifikan. Berikut ini disajikan hasil kerja siswa siswa yang memperoleh pembelajaran model CMI dan yang memperoleh pembelajaran model konvensional dalam menyelesaikan soal kemampuan specializing.

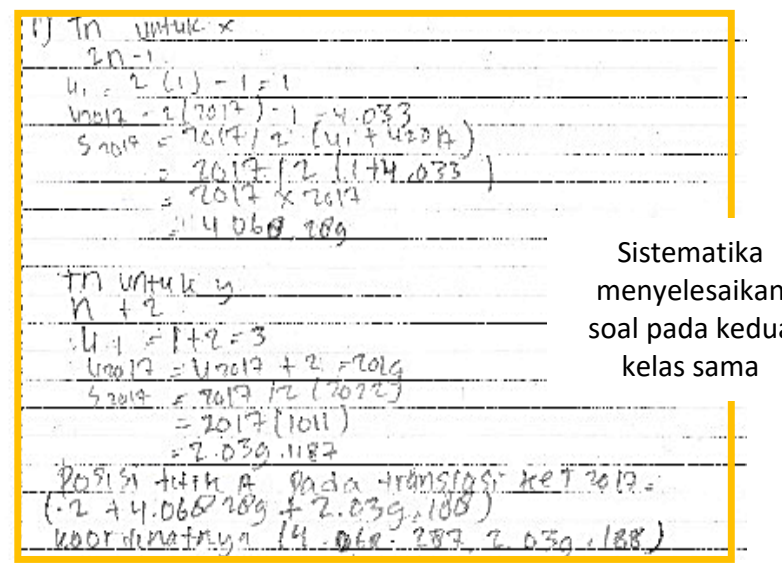

Model konvensional

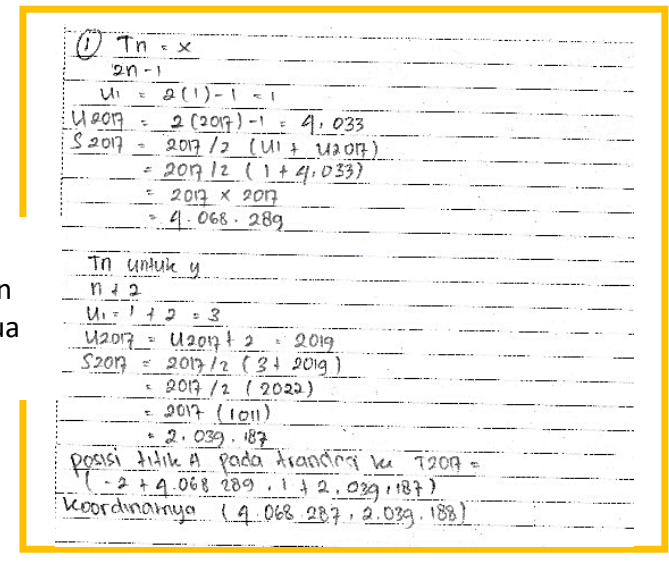

Model CMI

Gambar 2. Hasil Kerja Siswa pada Soal Tes Kemampuan Specializing 
Sementara itu, generalizing merupakan aspek dalam kemampuan mathematical thinking yang secara alamiah telah dimiliki oleh setiap orang (Delima et al., 2018). Sejalan dengan teori psikologi kognitif Gestalt, yang mengemukakan bahwa manusia memiliki tendensi untuk melengkapi atau mengisi pengalaman-pengalaman yang tidak lengkap, agar menjadi lebih berarti (Guberman, 2015). Model CMI melatih siswa untuk membuat sebuah generalisasi berdasarkan soal atau tugas yang diberikan. Tahap develop pada model CMI mengharuskan siswa untuk melihat apakah pada jawaban setiap soal/ tugas yang diberikan terdapat suatu pola atau tidak. Kegiatan generalisasi ini terus dilakukan pada tahap solidify sampai dengan ditemukan sebuah konjektur dari pola yang diberikan. Pada Gambar 1 diperlihatkan bahwa siswa yang memperoleh model CMI telah menemukan pola dari soal yang diberikan. Dengan demikian, cukup beralasan jika capaian kemampuan generalizing siswa yang memperoleh pembelajaran model CMI secara signifikan lebih baik daripada siswa yang memperoleh pembelajaran model konvensional.

Capaian kemampuan specializing, generalizing, conjecturing dan convincing siswa dengan PAM rendah dan tinggi, tidak berbeda secara signifikan antara siswa yang memperoleh pembelajaran model CMI dengan siswa yang memperoleh pembelajaran model konvensional. Sementara itu, pada siswa dengan PAM sedang, capaian kemampuan generalizing, conjecturing dan convincing mengalami perbedaan yang signifikan antara siswa yang memperoleh pembelajaran model CMI dengan siswa yang memperoleh pembelajaran model konvensional. Dengan kata lain, pembelajaran model CMI hanya efektif untuk mengkonstruksi kemampuan generalizing, conjecturing dan convincing pada siswa dengan PAM sedang saja. Hal ini sejalan dengan penelitian Yildirim dan Yavuzsoy Kose (2018), dan Uyangör (2019), yang mengemukakan bahwa siswa dalam setiap kelompok yang diteliti mampu melakukan proses specializing, berbeda dengan generalizing, conjecturing dan convincing. Kemampuan specializing dikembangkan dalam setiap pembelajaran matematika dengan model apa pun, karena pembelajaran matematika pada kurikulum 2013 memfasilitasi siswa untuk menyelesaikan sebuah masalah dengan melihat contoh terlebih dahulu (Setiyawan, 2017), sehingga jelas bahwa capaian kemampuan specializing siswa yang memperoleh pembelajaran model CMI tidak berbeda secara signifikan dengan siswa yang memperoleh pembelajaran model konvensional.

Pembelajaran model CMI memberikan kesempatan kepada siswa untuk berperan aktif dalam bertanya, menjelaskan jawaban soal matematis yang diperolehnya, maupun mentransfer pengetahuan yang mereka miliki dengan teman sekelasnya (Hendrickson et al., 2008). Model CMI menyediakan struktur pedagogis yang sangat lengkap bagi guru untuk 
membimbing siswa (Hendrickson et al., 2008). Penelitian ini menemukan bahwa pembelajaran dengan model CMI akan lebih efektif jika siswa dengan PAM rendah mendapatkan lebih banyak arahan dari guru dibandingkan dengan siswa lainnya.

Berdasarkan hasil observasi oleh observer, keterlaksanaan syntax model CMI pada penelitian ini telah sesuai dengan RPP yang direncanakan. Pada tahapan develop, siswa mulai diberikan stimulus untuk membuat spesialisasi atau membuat contoh sederhana dari soal atau tugas yang telah diberikan, dalam kemampuan mathematical thinking, kegiatan ini termasuk ke dalam proses specializing. Sementara itu, peran siswa pada tahap develop ini, diantaranya adalah memperhatikan setiap jawaban dari soal atau tugas yang diberikan guru untuk melihat apakah terdapat suatu pola atau tidak. Dengan kata lain, siswa dilatih untuk membuat sebuah generalisasi dari jawaban soal atau tugas yang diberikan. Dalam kemampuan mathematical thinking, kegiatan ini termasuk ke dalam proses generalizing (Stacey, 2006). Masih pada tahap develop, dari sebuah generalisasi yang diperoleh, siswa juga memiliki peran untuk membuat suatu konjektur. Dengan demikian, pada tahap ini juga siswa mulai melakukan proses conjecturing yang ada dalam kemampuan mathematical thinking. Konjektur ini disempurnakan secara terus menerus pada tahap solidify. Pada tahap solidify ini, siswa diarahkan untuk mulai memiliki argumen yang kuat tentang konjektur yang telah mereka buat sebelumnya. Selain itu, mereka juga mulai mengkritisi argumen yang dikemukakan oleh teman-temannya di kelas. Ini menunjukan bahwa, mereka sudah mulai melakukan convincing, mereka mencoba untuk meyakinkan dirinya sendiri, orang lain bahkan guru-nya tentang ide, strategi, dan/atau representasi yang mereka peroleh. Secara garis besar, cukup beralasan untuk mengatakan bahwa capaian kemampuan mathematical thinking siswa yang memperoleh pembelajaran model CMI lebih baik daripada siswa yang memperoleh pembelajaran model konvensional.

\section{Simpulan}

Capaian kemampuan mathematical thinking siswa yang memperoleh pembelajaran model CMI lebih baik daripada siswa yang memperoleh pembelajaran model konvensional. Perbedaan capaian kemampuan mathematical thinking antara siswa yang memperoleh pembelajaran model CMI dengan siswa yang memperoleh pembelajaran konvensional hanya terjadi pada siswa dengan PAM sedang. Terdapat perbedaan capaian kemampuan generalizing, conjecturing dan convincing antara siswa yang memperoleh pembelajaran model CMI dengan yang memperoleh pembelajaran konvensional. Perbedaan pencapaian kemampuan generalizing, conjecturing dan convincing antara siswa yang memperoleh 
pembelajaran model CMI dengan yang memperoleh pembelajaran model konvensional terjadi pada siswa dengan PAM sedang.

\section{Referensi}

Bass, H. (2005). Mathematics, mathematicians and mathematics education. Bulletin of the American Mathematical Society, 42(4), 417-430. https://doi.org/10.1090/S0273-097905-01072-4.

Breen, S., \& O'shea, A. (2010). Mathematical thinking and task design. Irish Mathematics Society Bulletin, 66(1), 39-49.

Cohen, L., Manion, L., \& Morrison, K. (2007). Research methods in education (6 ed.). New York: Routledge. https://doi.org/10.4324/9780203029053.

Delima, N. (2017). A relationship between problem solving ability and students' $\begin{array}{lllll}\text { mathematical thinking. Infinity } & \text { Journal, }\end{array}$ https://doi.org/10.22460/infinity.v6i1.231.

Delima, N., \& Fitriza, R. (2017). Pengembangan model comprehensive instruction (CMI) dalam membangun kemampuan mathematical thinking siswa. JNPM (Jurnal Nasional Pendidikan Matematika), 4(1), 1-25. https://doi.org/10.33603/jnpm.v1i1.248.

Delima, N., Kusumah, Y. S., \& Fatimah, S. (2019). Improving mathematics self-concept through comprehensive mathematics instruction model. Journal of Physics: Conference Series, 1315(1). https://doi.org/10.1088/1742-6596/1315/1/012076.

Delima, N., Rahmah, M. A., \& Akbar, A. (2018). The analysis of students' mathematical thinking based on their mathematics self-concept. Journal of Physics: Conference Series, 1108(1). https://doi.org/10.1088/1742-6596/1108/1/012104.

Dick, W., \& Lou, C. (2005). The systematic design of instructional third education. London: Pearson.

Diezmann, C. M. (2004). Assessing learning from mathematical inquiry: Challenges for students, teachers and researchers. Proceedings Mathematical Association of Victoria Conference, 80-85. Diambil dari http://citeseerx.ist.psu.edu/viewdoc/download?doi=10.1.1.570.4931\&rep=rep1\&type=p df.

Ersoy, E., \& Güner, P. (2015). The place of problem solving and mathematical thinking in the mathematical teaching. The Online Journal of New Horizons in Education, 5(1), 120 130.

Fernández, C., Sánchez-Matamoros, G., Valls, J., \& Callejo, M. L. (2018). Noticing students' mathematical thinking: Characterization, development and contexts. Avances de Investigacion en Educacion Matematica, 13, 39-61. https://doi.org/10.35763/aiem.v0i13.229.

Gibney, J. (2014). Provoking mathematical thinking: Experiences of doing realistic mathematics tasks with adult numeracy teachers. Adults Learning Mathematics, 9(2), 97-115.

Guberman, S. (2015). On Gestalt theory principles. Gestalt Theory, 37(1), 25-44.

Harefa, A. O. (2013). Penerapan teori pembelajaran Ausebel dalam pembelajaran. Majalah Ilmiah Warta Dharmawangsa, 36(1), 43-55. Diambil dari https://media.neliti.com/media/publications/168547-ID-penerapan-teori-pembelajaranausebel-dal.pdf.

Hendrickson, S., Hilton, S. C., \& Bahr, D. (2008). The comprehensive mathematics instruction (CMI) framework: A new lens for examining teaching and learning in the mathematics classroom. Utah Mathematics Teacher, 1(1), 44-52. 
Kemdikbud. (2019). Ringkasan eksekutif hasil ujian nasional 2019 masukan untuk pembelajaran di sekolah SMA/MA. Jakarta: Puspendik Balitbang Kemdikbud.

Mason, J. (2020). Generating worthwhile mathematical tasks in order to sustain and develop mathematical thinking. Sustainability, 12(14), 1-12. https://doi.org/10.3390/su12145727.

Mason, J., Burton, L., \& Stacey, K. (2010). Thinking mathematically (2 ed.). London: Pearson.

Mason, J., \& Johnston-Wilder, S. (2004). Designing and using mathematical tasks. London: Tarquin Press.

OECD. (2019). PISA 2018 results. combined executive summaries. Paris: OECD Publishing. https://doi.org/10.1787/17457005-en.

Setiyawan, H. (2017). Pembelajaran matematika model PBL pada mata pelajaran matematika materi luas bidang pada siswa kelas III SD. Jurnal Inovasi, XIX(1), 1-17. Diambil dari https://erepository.uwks.ac.id/276/1/JURNAL_HERY_FBS.pdf.

Stacey, K. (2006). What is mathematical thinking and why is it important? Australia: University of Melbourne. Diambil dari https://www.researchgate.net/publication/254408829.

Uyangör, S. M. (2019). Investigation of the mathematical thinking processes of students in mathematics education supported with graph theory. Universal Journal of Educational Research, 7(1), 1-9. https://doi.org/10.13189/ujer.2019.070101.

Yildirim, D., \& Yavuzsoy Kose, N. (2018). Mathematical thinking processes of secondary school students in polygon problems. Abant İzet Baysal Üniversitesi Ë̆itim Fakültesi Dergisi, 18(1), 605-633. Diambil dari https://dergipark.org.tr/en/download/articlefile/376448. 